\title{
The effects of subchorionic hematoma on pregnancy outcome in patients with threatened abortion
}

\author{
Yavuz Emre Şükürr , Göksu Göçl, Osman Köse², Gökhan Açmaz³, Batuhan Özmen', \\ Cem Somer Atabekoğlu ${ }^{1}$, Acar Koç ${ }^{1}$ Feride Söylemez ${ }^{1}$ \\ 'Department of Obstetrics and Gynaecology, Ankara University Faculty of Medicine, Ankara, Turkey \\ ${ }^{2}$ Department of Obstetrics and Gynaecology, Yenimahalle State Hospital, Ankara, Turkey \\ ${ }^{3}$ Department of Obstetrics and Gynaecology, Kayseri Education and Research Hospital, Kayseri, Turkey
}

\section{Abstract}

Objective: To assess the effects of ultrasonographically detected subchorionic hematomas on pregnancy outcomes in patients with vaginal bleeding within the first half of pregnancy.

Material and Methods: Patients diagnosed with threatened abortion due to painless vaginal bleeding and who were followed up in an inpatient service during the first vaginal bleeding between January 2009 and December 2010 were included in this retrospective cohort study. Patients were divided into two groups according to the presence of subchorionic hematoma. Miscarriage rates and pregnancy outcomes of ongoing pregnancies were compared between the groups.

Results: There were no statistically significant differences between the groups regarding demographic parameters, including age, parity, previous miscarriage history, and gestational age at first vaginal bleeding. While 13 of 44 pregnancies (29.5\%) with subchorionic hematoma resulted in miscarriage, 25 of 198 pregnancies $(12.6 \%)$ without subchorionic hematoma resulted in miscarriage $(p=.010)$. The gestational age at miscarriage and the duration between first vaginal bleeding and miscarriage were similar between the groups. The outcome measures of ongoing pregnancies, such as gestational week at delivery, birth weight, and delivery route, were also similar between the groups.

Conclusion: Ultrasonographically detected subchorionic hematoma increases the risk of miscarriage in patients with vaginal bleeding and threatened abortion during the first 20 weeks of gestation. However, it does not affect the pregnancy outcome measures of ongoing pregnancies. (J Turk Ger Gynecol Assoc 2014; 15: 239-42)

Key words: Abortion, threatened, miscarriage, spontaneous, pregnancy outcome

Received: 02 September, $2014 \quad$ Accepted: 09 October, 2014

\section{Introduction}

Vaginal bleeding is a frequent complication of pregnancy during the first trimester, with an incidence of $16 \%-25 \%$ (1). Intrauterine bleeding without cervical dilatation and tenderness during the early pregnancy period is defined as threatened abortion. Generally, it is not associated with pain and excessive bleeding. These bleedings result in maternal anxiety and may be associated with fetal/maternal adverse outcomes (2-4). One of the suggested mechanisms for threatened abortion is placental dysfunction, which can also cause several late complications, such as preeclampsia, preterm labor, preterm birth, placental abruption, placenta previa, intrauterine growth restriction, and perinatal mortality $(2,3)$. Similarly, insufficient angiogenesis is associated with early pregnancy losses, and maternal serum AFP and $\beta$-hCG are suggested to be used as markers of angiogenesis in the first trimester (5). Together with these markers, chronic inflam- mation of the decidua might also be the underlying cause of early pregnancy bleedings.

Intrauterine hemorrhages are commonly observed features on ultrasound examinations, especially among patients with clinically evident bleeding in early pregnancy, and the incidence has been reported to be $4 \%-22 \%$ (6). Subchorionic hematomas (SCHs) usually appear as hypoechoic or anechoic crescent-shaped areas on ultrasonography. Although the exact etiology is uncertain, they are believed to result from partial detachment of the chorionic membranes from the uterine wall (7). Uterine malformations, history of recurrent pregnancy loss, and infections are the possible predisposing factors (8-10). The clinical significance of $\mathrm{SCH}$ remains controversial (11-14). It is also not certain if these hemorrhages result in abortion. However, according to the results of a recent meta-analysis, the presence of $\mathrm{SCH}$ increases the risk of early or late pregnancy loss by 2-fold (15). It is suggested that the presence of $\mathrm{SCH}$ increases the risk of an adverse obs- 
tetric outcome, and fetal outcome is associated with the size of the hematoma, maternal age, and gestational age $(16,17)$.

The aim of the present retrospective cohort study was to assess the effects of ultrasonographically detected $\mathrm{SCH}$ on pregnancy outcomes in patients with vaginal bleeding within the first half of pregnancy.

\section{Material and Methods}

In this retrospective cohort study, patients with threatened abortion $(n=242)$ who were followed at a university-based perinatology clinic between January 2009 and December 2010 were recruited. The study was approved by the institutional review board of Ankara University School of Medicine. The inclusion criteria were hospitalization due to threatened abortion, singleton pregnancy, gestational age $<20$ weeks, and being followed up at our clinic until the end of the pregnancy. The exclusion criteria were a diagnosis of incipient abortion, no fetal cardiac activity, gestational age $\geq 20$ weeks, multiple pregnancy, and recurrent pregnancy loss. The study group consisted of 44 patients with SCHs observed on ultrasonography, and the control group consisted of 198 patients without SCHs. All included patients were hospitalized for at least 3 days following the first vaginal bleeding episode. All patients were administered prophylactic progesterone treatment in oral (Progestan capsule; Koçak Farma, İstanbul, Turkey), vaginal (Crinone 8\% gel; Serono, İstanbul, Turkey), or intramuscular (Proluton depot ampule; Schering Alman, İstanbul, Turkey) forms. Subsequent to discharge from the hospital, patients went on routine antenatal follow-up programs. The pregnancy outcomes were compared between the study and control groups. In patients whose pregnancies resulted in miscarriage, the gestational age at miscarriage and the duration between the first bleeding and miscarriage were compared. In patients whose pregnancies resulted in delivery, gestational age at labor, birth weight, preterm delivery, and cesarean section rates were compared between the groups.

\section{Statistical analysis}

Statistical Package for the Social Sciences (SPSS) 15.0 for Windows (Chicago, IL, USA) was used for all statistical analyses. Shapiro-Wilk test was used to test the distribution of normality. According to the results, non-parametric tests were preferred. Continuous variables were compared with Kruskal-Wallis test. Categorical variables were compared with chi-square test or Fisher's exact test where appropriate. A p value of $<.05$ was considered statistically significant.

\section{Results}

The incidence of $\mathrm{SCH}$ among patients with threatened abortion was $18.2 \%$ (44/242) for this population. The demographic variables of the study and control groups are presented in Table 1. The mean ages of the patients with and without $\mathrm{SCH}$ were $29.5 \pm 6.2$ and $29.0 \pm 5.5$ years, respectively $(p=.624)$. The groups were comparable regarding previous parity and miscarriage histories (Table 1). Similarly, the groups were comparable regarding gestational age at the first vaginal bleeding $(9.3 \pm 2.8$ vs. $10.2 \pm 3.3$ weeks, respectively; $p=.085$ ).

Table 2 summarizes the parameters of both groups regarding miscarriage; 13 of 44 pregnancies with $\mathrm{SCH}$ resulted in miscarriage $(29.5 \%)$, while 25 of 198 pregnancies with $\mathrm{SCH}$ resulted in miscarriage $(12.6 \%)(p=.010)$. The gestational age at miscarriage was similar between the study and control groups $(10.8 \pm 3.6$ vs. $10.9 \pm 4.8$ weeks, respectively; $p=.581)$. Similarly, there was no statistically significant difference between the study and control groups regarding duration between the first vaginal bleeding and miscarriage (16.4 \pm 23.8 vs. $9.0 \pm 7.5$ days, respectively; $\mathrm{p}=.436$ ).

Table 3 summarizes the pregnancy outcomes of 204 patients whose pregnancy resulted in delivery. The mean gestational ages at delivery were $37.4 \pm 4.1$ weeks in 31 patients with $\mathrm{SCH}$

Table 1. Demographic parameters of the study and control groups

\begin{tabular}{|l|c|c|c|}
\hline & $\begin{array}{c}\text { SCH (+) } \\
\mathbf{n = 4 4}\end{array}$ & $\begin{array}{c}\text { SCH (-) } \\
\mathbf{n = 1 9 8}\end{array}$ & $\mathbf{p}$ \\
\hline Age (years) & $29.5 \pm 6.2$ & $29.0 \pm 5.5$ & .624 \\
\hline Parity (n) & $.5 \pm .8$ & $.6 \pm .8$ & .581 \\
\hline Previous miscarriage (n) & $.5 \pm .7$ & $.4 \pm .8$ & .657 \\
\hline $\begin{array}{l}\text { Gestational age at first } \\
\text { vaginal bleeding (weeks) }\end{array}$ & $9.3 \pm 2.8$ & $10.2 \pm 3.3$ & .085 \\
\hline SCH: subchorionic hematoma & & \\
\hline
\end{tabular}

Table 2. Comparison of miscarriage and related parameters between study and control groups

\begin{tabular}{|l|c|c|c|}
\hline & $\begin{array}{c}\text { SCH (+) } \\
\mathbf{n = 4 4}\end{array}$ & $\begin{array}{c}\text { SCH (-) } \\
\mathbf{n = 1 9 8}\end{array}$ & $\mathbf{p}$ \\
\hline Miscarriage, n (\%) & $13(29.5)$ & $25(12.6)$ & .010 \\
\hline $\begin{array}{l}\text { Within pregnancies } \\
\text { resulting in miscarriage }\end{array}$ & $\mathrm{n}=13$ & $\mathrm{n}=25$ & .581 \\
\hline $\begin{array}{l}\text { Gestational age at } \\
\text { miscarriage (weeks) }\end{array}$ & $10.8 \pm 3.6$ & $10.9 \pm 4.8$ & .436 \\
\hline $\begin{array}{l}\text { Duration between first } \\
\text { bleeding and miscarriage } \\
\text { (days) }\end{array}$ & $16.4 \pm 23.8$ & $9.0 \pm 7.5$ & \\
\hline SCH: subchorionic hematoma & & & \\
\hline
\end{tabular}

Table 3. Comparison of pregnancy outcomes in patients whose pregnancy resulted in delivery

\begin{tabular}{|l|c|c|c|}
\hline & $\begin{array}{c}\text { SCH (+) } \\
\mathbf{n = 4 4}\end{array}$ & $\begin{array}{c}\text { SCH (-) } \\
\mathbf{n = 1 9 8}\end{array}$ & $\mathbf{p}$ \\
\hline $\begin{array}{l}\text { Gestational age at delivery } \\
\text { (weeks) }\end{array}$ & $37.4 \pm 4.1$ & $37.4 \pm 3.6$ & .962 \\
\hline Preterm delivery, n (\%) & $5(16.1)$ & $44(25.4)$ & .362 \\
\hline Birth weight (kg) & $2958 \pm 810$ & $3004 \pm 763$ & .792 \\
\hline Cesarean section, n (\%) & $13(41.9)$ & $80(45.9)$ & .701 \\
\hline SCH: subchorionic hematoma & & \\
\hline
\end{tabular}


and $37.4 \pm 3.6$ weeks in 173 patients without $\mathrm{SCH}(\mathrm{p}=.962)$. There was no statistically significant difference between the study and control groups regarding preterm birth rate $(16.1 \%$ vs. $25.4 \%$, respectively; $\mathrm{p}=.362$ ). Similarly, the birth weights were comparable between the groups $(2958 \pm 810 \mathrm{~g}$ vs. $3004 \pm 763 \mathrm{~g}$, respectively; $\mathrm{p}=.792)$. The cesarean section rates were also similar between the study and control groups (41.9\% vs. 45.9\%, respectively; $p=.701$ ).

\section{Discussion}

The results obtained from the present study revealed that the presence of $\mathrm{SCH}$ in patients with threatened abortion is an important factor for the continuation of pregnancy. The presence of $\mathrm{SCH}$ in patients with threatened abortion increases the risk of miscarriage. However, it does not affect the gestational age at miscarriage or the duration between the first bleeding and miscarriage. In patients whose pregnancies resulted in delivery, gestational age at labor, birth weight, preterm delivery, and cesarean section rates were not affected by the presence of SCH. Previously, several studies have investigated the effects of SCH on pregnancy outcomes. Ball et al. (18) evaluated 238 patients with ultrasonographically detected $\mathrm{SCH}$ in a retrospective casecontrol study and reported a significant association between $\mathrm{SCH}$ and miscarriage and preterm delivery rates. They also reported increasing pregnancy loss rates with increasing SCH size. Similarly Nagy et al. (19) compared 187 patients who had SCH with 6488 controls, and they found increased miscarriage, intrauterine growth restriction, and preterm delivery rates in the presence of SCH. However, they failed to show an association between the size and location of the $\mathrm{SCH}$ and ongoing pregnancy outcome measures. In a retrospective cohort study, Norman et al. (20) evaluated 63,966 patients who had an ultrasonographic evaluation before 22 weeks of gestation and reported that the incidence of $\mathrm{SCH}$ was $1.7 \%$. They found that the detection of an $\mathrm{SCH}$ during routine second-trimester ultrasonography was associated with more than a 2-fold increased risk of placental abruption, regardless of whether the woman reported bleeding in the early half of pregnancy. They also identified that women with $\mathrm{SCH}$ were at increased risk of preterm delivery. However, in the aforementioned studies, SCHs were defined during the routine first- or second-trimester ultrasonography, and not all patients with an $\mathrm{SCH}$ had threatened abortion. Vaginal bleeding occurs in 25\% of pregnancies in the first 20 weeks, and half of these result in miscarriage (16). Hence, it is important to identify the risk factors of threatened abortion and the factors that can affect the outcome. In a retrospective cohort trial, Ben-Haroush et al. (21) assessed 2556 pregnant patients who were admitted with vaginal bleeding during the first 20 gestational weeks. The incidence of $\mathrm{SCH}$ was $9 \%$. They reported that gestational age at diagnosis, size of $\mathrm{SCH}$, and duration of bleeding did not affect the pregnancy outcome. They also reported significantly decreased miscarriage rates with bed rest. However, Bennett et al. (17) reported that increasing $\mathrm{SCH}$ size increases the risk of miscarriage. In a prospective cohort study, Pedersen and Mantoni followed up 342 pregnancies with vaginal bleeding between 9 to 20 gestational weeks, in which 18\% had SCH (12). They found no association between the presence of $\mathrm{SCH}$ and miscarriage or preterm delivery risks. In another retrospective case-control study, Johns et al. (22) reported that first-trimester vaginal bleedings were associated with adverse pregnancy outcomes, but the presence of $\mathrm{SCH}$ had no effect on the prognosis. According to the results of a recent meta-analysis evaluating 1735 patients with $\mathrm{SCH}$ from 7 studies, the presence of $\mathrm{SCH}$ increases the risks of early and late pregnancy loss, miscarriage, and preterm premature rupture of membranes (15).

In a prospective study from Turkey, the size of the $\mathrm{SCH}$ was suggested to be the primary risk factor for miscarriage in patients with first-trimester vaginal bleeding (23). Uluğ et al. (24) reported that first-trimester bleedings were associated with preterm delivery and low birth weight. However, they found no relationship between the prognosis and presence or size of the $\mathrm{SCH}$. In another Turkish case-control study, Özkaya et al. (25) reported the outcomes of 43 patients with $\mathrm{SCH}$, and they found that the presence of $\mathrm{SCH}$ increases the risks of miscarriage and intrauterine growth restriction but not preterm delivery. The results of our study were partially concordant with the literature, as we could only show that the presence of SCH increased the risk of miscarriage. However, we failed to show any significant relationship between the presence of $\mathrm{SCH}$ and ongoing pregnancy outcome measures.

The underlying mechanism of how $\mathrm{SCH}$ causes adverse pregnancy outcomes is still controversial. One of the possible mechanisms is the premature perfusion of the intervillous space, as occurs with subchorionic hemorrhage, before the development of placental adaptations to cope with oxidative stress (26). Another possible mechanism might be the underlying cause of the subchorionic bleeding and secondary mechanical effects of the hematoma. Shallow trophoblast invasion and impaired angiogenesis with resultant friable blood vessels may predispose one to subchorionic hemorrhage, as well as adverse outcomes (15). The presence of a hematoma, especially in a retroplacental location, may create an area of weakness, where further separation of the placenta from the uterine wall may occur, resulting in placental abruption (15). Our results support the estimated mechanical effect of $\mathrm{SCH}$ that can cause miscarriage. The presence of an $\mathrm{SCH}$ and detachment of the gestational sac from the endometrium may result in miscarriage. However, if the gestational sac survives, reattachment to the endometrial wall might be enough for further progression of the pregnancy without any other adverse effects.

In conclusion, $\mathrm{SCH}$ in patients with threatened abortion during the first half of the pregnancy increases the risk of miscarriage. However, it is not absolute if the presence of an $\mathrm{SCH}$ increases the adverse pregnancy outcome risk in ongoing pregnancies or not, because almost all of the previously reported studies were retrospective. Large prospective randomized studies are required to determine the true role of $\mathrm{SCH}$ in the prognosis of ongoing pregnancies.

\section{Ethics Committee Approval: N/A}

Informed Consent: N/A.

Peer-review: Externally peer-reviewed. 
Author contributions: Concept - Y.E.S., G.G., O.K.; Design - Y.E.S.,, O.K., G.A.; Supervision - B.Ö., A.K., F.S.; Resource - Y.E.S., G.G.; Materials Y.E.S., G.G.; Data Collection\&/or Processing - Y.E.Ş., G.G.; Analysis\&/or Interpretation - Y.E.S.., G.A.; Literature Search - Y.E.Ş.; Writing - Y.E.Sु.; Critical Reviews - B.Ö., A.K., F.S.

Conflict of Interest: No conflict of interest was declared by the authors.

Financial Disclosure: The authors declared that this study has received no financial support.

\section{References}

1. Farrell $\mathrm{T}$, Owen P. The significance of extrachorionic membrane separation in threatened miscarriage. Br J Obstet Gynaecol 1996; 103: 926-8. [CrossRef]

2. Saraswat L, Bhattacharya S, Maheshwari A, Bhattacharya S. Maternal and perinatal outcome in women with threatened miscarriage in the first trimester: A systematic review. BJOG 2010; 117: 245-57. [CrossRef]

3. Weiss JL, Malone FD, Vidaver J, Ball RH, Nyberg DA, Comstock CH, et al. Threatened abortion: a risk factor for poor pregnancy outcome, a population-based screening study. Am J Obstet Gynecol 2004; 190: 745-50. [CrossRef]

4. Wijesiriwardana A, Bhattacharya S, Shetty A, Smith N, Bhattacharya $\mathrm{S}$. Obstetric outcome in women with threatened miscarriage in the first trimester. Obstet Gynecol 2006; 107: 557-62. [CrossRef]

5. Kutluer G, Çiçek NM, Moraloğlu Ö, Ertargın P, Sarıkaya E, Artar I, Erdem Ö. Low VEGF expression in conceptus material and maternal serum AFP and $\beta$-hCG levels as indicators of defective angiogenesis in first-trimester miscarriages. J Turk Ger Gynecol Assoc 2012; 13: 111-7. [CrossRef]

6. Pearlstone M, Baxi L. Subchorionic hematoma: A review. Obstet Gynecol Surv 1993; 48: 65-8. [CrossRef]

7. Maso G, D'Ottavio G, De Seta F, Sartore A, Piccoli M, Mandruzzato G. First-trimester intrauterine hematoma and outcome of pregnancy. Obstet Gynecol 2005; 105: 339-44. [CrossRef]

8. Mandruzzato GP, D'Ottavio G, Rustico MA, Fontana A, Bogatti P. The intrauterine hematoma: diagnostic and clinical aspects. J Clin Ultrasound 1989; 17: 503-10. [CrossRef]

9. Kaufman AJ, Fleischer AC, Thiema GA, Shah DM, James AE Jr. Separated chorioamnion and elevated chorion: sonographic features and clinical significance. J Ultrasound Med 1985; 4: 119-25.

10. Queck M, Berle P. Spontaneous abortion after vaginal hemorrhage in intact early pregnancy: An etiologic analysis. Geburtshilfe Frauenheilkd 1992; 52: 553-6. [CrossRef]

11. Mantoni M, Pederson JF. Intrauterine hematoma: An ultrasonic study of threatened abortion. BJOG 1981; 88: 47-51. [CrossRef]
12. Pedersen JF, Mantoni M. Large intrauterine haematomata in threatened miscarriage: frequency and clinical consequences. BJOG 1990; 97: 75-7. [CrossRef]

13. Bloch C, Altchek A, Levy-Ravetch M. Sonography in early pregnancy: the significance of subchorionic hemorrhage. Mt Sinai J Med 1989; 56: 290-2.

14. Borlum KG, Thomsen A, Clausen I, Eriksen G. Long term prognosis of pregnancies with intrauterine hematomas. Obstet Gynecol 1989; 74: 231-3.

15. Tuuli MG, Norman SM, Odibo AO, Macones GA, Cahill AG. Perinatal outcomes in women with subchorionic hematoma Obstet Gynecol 2011; 117: 1205-12. [CrossRef]

16. Abu-Yousef MM, Bleider JJ, Williamson RA, Weiner CP. Subchorionic hemorrhage: Sonographic diagnosis and clinical significance. Am J Roentgenol 1987; 149: 737-40. [CrossRef]

17. Bennett GL, Bromley B, Lieberman E, Benacerraf BR. Subchorionic hemorrhage in first-trimester pregnancies: prediction of pregnancy outcome with sonography. Radiology 1996; 200: 803-6. [CrossRef]

18 Ball RH, Ade CM, Schoenborn JA, Crane JP. The clinical significance of ultrasonographically detected subchorionic hemorrhages. Am J Obstet Gynecol 1996; 174: 996-1002. [CrossRef]

19. Nagy S, Bush M, Stone J, Lapinski RH, Gardo S. Clinical significance of subchorionic and retroplacental hematomas detected in the first trimester of pregnancy. Obstet Gynecol 2003; 102: 94-100. [CrossRef]

20. Norman SM, Odibo AO, Macones GA, Dicke JM, Crane JP, Cahill AG. Ultrasound-detected subchorionic hemorrhage and the obstetric implications. Obstet Gynecol 2010; 116(2Pt1): 311-5. [CrossRef]

21. Ben-Haroush A, Yogev Y, Mashiach R, Meizner I. Pregnancy outcome of threatened abortion with subchorionic hematoma: possible benefit of bed-rest? IMAJ 2003; 5: 422-4.

22. Johns J, Hyett J, Jauniaux E. Obstetric outcome after threatened miscarriage with and without a hematoma on ultrasound. Obstet Gynecol 2003; 102: 483-7. [CrossRef]

23. Möröy P, Kaymak O, Okyay E, Çelen S, Özkale D, Atayar YY, et al. The effects of first trimester subchorionic hematomas on pregnancy outcome. Türkiye Klinikleri J Gynecol Obst 2004; 14: 247-51.

24. Uluğ U, Jozwiak EA, Tosun S, Bahçeci M. Preterm delivery risk among pregnancies with history of first trimester vaginal bleeding and intrauterin hematoma. Zeynep Kamil Tıp Bülteni 2006; 37: 47-51.

25. Özkaya E, Altay M, Gelişen O. Significance of subchorionic haemorrhage and pregnancy outcome in threatened miscarriage to predict miscarriage, pre-term labour and intrauterine growth restriction. J Obstet Gynaecol 2011; 31: 210-2.

26. Jauniaux E, Watson AL, Hempstock J, Bao YP, Skepper JN, Burton GJ. Onset of maternal arterial blood flow and placental oxidative stres. A possible factor in human early pregnancy failure. Am J Pathol 2000; 157: 2111-22. [CrossRef] 